Tavares, LP, Oliveira Jr, FL \& Magalhães, M. (2020). Analysis of President Jair Bolsonaro's speeches in the midst of the pandemic: is the coronavirus just a "little flu"? Research, Society and Development, 9(7): 1-19. e609974469.

\title{
Análise dos discursos do Presidente Jair Bolsonaro em meio à pandemia: o coronavírus é só uma "gripezinha"?
}

\section{Analysis of President Jair Bolsonaro's speeches in the midst of the pandemic: is the coronavirus just a "little flu"? \\ Análisis de los discursos del presidente Jair Bolsonaro en medio de la pandemia: ¡el coronavirus es solo una "pequeña gripe"?}

Recebido: 13/05/2020 | Revisado: 15/05/2020 | Aceito: 20/05/2020 | Publicado: 27/05/2020

\section{Leonardo Pereira Tavares}

ORCID: http://orcid.org/0000-0003-0696-1665

Universidade Federal de Campina Grande, Brasil

E-mail: leonardoptavares@outlook.com

Francisco Lima de Oliveira Júnior

ORCID: http://orcid.org/0000-0001-5654-4726

Universidade Federal de Campina Grande, Brasil

E-mail: franjunior64@ @otmail.com

Marina Magalhães

ORCID: http://orcid.org/0000-0002-1124-8269

Universidade Federal de Campina Grande, Brasil

E-mail: marinamagalhaes@msn.com

\section{Resumo}

No final de 2019 surgiu na China uma doença infeciosa causada pelo coronavírus da síndrome respiratória aguda grave 2, atualmente denominada de COVID-19. Dentro de uma sociedade globalizada, a propagação mundial do novo coronavírus, altamente contagioso, era algo inevitável. O Brasil, até o dia 7 de maio de 2020, apontava um balanço oficial do Ministério da Saúde de 9.146 mortes e 135.106 casos confirmados, além de uma curva ascendente da doença. A partir do entendimento de que todo e qualquer posicionamento diante desta situação pode custar vidas, este estudo tem como objetivo analisar cinco discursos do presidente Jair Messias Bolsonaro em meio à pandemia, dentre eles aquele proferido durante a comitiva internacional em Miami no dia 9 de março, o pronunciamento oficial do dia 24 de 
março, e a transmissão de Páscoa do dia 12 de abril, todos acontecidos no ano de 2020. Desse modo, parte de uma contextualização histórica sobre a pandemia da gripe espanhola, que surgiu em 1918 e deixou milhares de mortos no Brasil e no mundo, para analisar um recorte dos discursos do presidente da República durante a atual pandemia, surgida aproximadamente um século depois. O presente artigo, de natureza teórico-analítica, foi desenvolvido a partir de revisões bibliográficas e de análises dos discursos de Jair Bolsonaro propagados através de websites, entrevistas, artigos e revistas, que revelam as tentativas de negação ou minimização dos riscos da doença.

Palavras-chave: Coronavírus; Discurso presidencial; Pandemia; Mídia; Jair Bolsonaro.

\begin{abstract}
At the end of 2019, an infectious disease caused by the severe acute respiratory syndrome coronavirus 2, currently known as COVID-19, appeared in China. Within a globalized society, the worldwide spread of the new and highly contagious coronavirus was inevitable. Until May 7, 2020 Brazil indicated, through an official balance sheet prepared by the Ministry of Health, a number of 9,146 deaths and 135,106 confirmed cases, in addition to an upward curve of the disease. Based on the understanding that any position in the face of this situation can cost lives, this study aims to analyze five speeches by president Jair Messias Bolsonaro in the midst of the pandemic, among them that given during the international delegation in Miami on March 9, the official pronouncement on March 24, and the Easter broadcast on April 12, all of which took place in the year 2020. Thus, this text starts from a historical contextualization about the Spanish flu pandemic, which emerged in 1918 and killed thousands of people in Brazil and worldwide, to analyze an excerpt from the speeches of the President of the Republic during the current pandemic, which occurred approximately one century later. The present article, of a theoretical-analytical nature, was developed from bibliographic reviews and analyzes of Jair Bolsonaro's speeches propagated through websites, interviews, articles and magazines, that reveal attempts to deny or minimize the risks of the disease.
\end{abstract}

Keywords: Coronavirus; Presidential speech; Pandemic; Media; Jair Bolsonaro.

\title{
Resumen
}

A finales de 2019, apareció en China una enfermedad infecciosa causada por el coronavirus 2 del síndrome respiratorio agudo severo, actualmente conocido como COVID-19. Dentro de una sociedad globalizada, la propagación mundial del nuevo y altamente contagioso 
coronavirus era inevitable. Hasta el 7 de mayo de 2020, Brasil indicó, a través de un balance oficial preparado por el Ministerio de Salud, un número de 9.146 muertes y 135.106 casos confirmados, además de una curva ascendente de la enfermedad. Basado en el entendimiento de que cualquier posición frente a esta situación puede costar vidas, este estudio tiene como objetivo analizar cinco discursos del presidente Jair Messias Bolsonaro en medio de la pandemia, entre ellos el que se dio durante la delegación internacional en Miami el 9 de marzo, el pronunciamiento oficial el 24 de marzo y la transmisión de Pascua el 12 de abril, todo lo cual tuvo lugar en el año 2020. Por lo tanto, este texto parte de una contextualización histórica sobre la pandemia de gripe española, que surgió en 1918 y mató a miles de personas en Brasil y en todo el mundo, para analizar un extracto de los discursos del presidente de la República durante la pandemia actual, que ocurrió aproximadamente un siglo después. El presente artículo, de carácter teórico-analítico, se desarrolló a partir de revisiones bibliográficas y análisis de los discursos de Jair Bolsonaro propagados a través de sitios web, entrevistas, artículos y revistas, que revelan los intentos de negar o minimizar los riesgos de la enfermedad.

Palabras clave: Coronavirus; Discurso presidencial; Pandemia; Medios de comunicación; Jair Bolsonaro.

\section{Introdução}

Em dezembro de 2019 surgem no mundo pessoas infectadas por um novo coronavírus denominado como COVID-19. Tal vírus ataca os pulmões provocando síndrome respiratória, apresentando sintomas comuns que podem incluir tosse seca, febre e cansaço, além de sintomas graves como febre alta, pneumonia e dificuldade para respirar (Organização PanAmericana da Saúde/Organização Mundial da Saúde Brasil, 2020).

Em Wuhan, capital de uma província chinesa chamada Hubei, foram identificados os primeiros casos que levariam à considerável pandemia que atemoriza a sociedade contemporânea. Segundo Surveillances (2020), o vírus rapidamente se espalhou, por cerca de 1.386 municípios e distritos em 31 províncias chinesas. Até o ultimo dia de fevereiro já havia o registro de 79.824 pessoas infectadas com o vírus apenas na China (Nippon Hōsō Kyōkai, 2020).

Embora algumas pessoas ainda não tivessem conhecimento sobre o vírus, este foi estudado há alguns anos na China e em outros países. Na Tunísia, país do continente africano, Abroug (2014) desenvolveu um estudo de caso em que investiga uma família infectada já em 
2013, pelo que se denominou como coronavírus da síndrome respiratória do Oriente Médio (MERS-CoV), doença de sintomas bastantes parecidos com os do COVID-19, de rápido contágio e grande propagação. Contudo, estudos mais recentes realizados na China sobre o novo coronavírus confirmam que uma das principais preocupações é a mutação viral, uma vez que em alguns casos foi possível identificar uma mutação capaz de tornar a infecção ainda mais agressiva (Tang et al., 2020).

Em um mundo globalizado, tal vírus não demoraria para se espalhar para outros países e continentes. Em um estudo sobre microrganismos, Stefan Ujvari já afirmava que:

Um doente pode dar a volta ao redor do mundo em período curto de tempo. Com isso, as epidemias se disseminariam pelo planeta com maior facilidade. A pneumonia asiática de 2003 partiu do Sudeste Asiático e alcançou a Europa e a América. O mundo prendeu a respiração diante do receio de uma epidemia globalizada. As manchetes dos jornais da imprensa escrita e falada não pouparam espaços para tal epidemia. Hoje, as notícias enfocam a "gripe aviária". Esperamos uma nova pandemia mundial de gripe a qualquer momento. Teríamos então uma epidemia mundial semelhante à "gripe espanhola" de 1918 (Ujvari, 2008, p.171).

O mundo passou por grandes pandemias, como peste bubônica, varíola, cólera, dentre outras. Uma das pandemias que deixou maior impacto global foi a "gripe espanhola", surgida em 1918, "atingindo em torno de 500 milhões de pessoas em várias partes do planeta e provocando pelo menos 22 milhões de óbitos entre 1918 e 1919, bem mais que os oito milhões de mortos na Primeira Guerra Mundial" (Ujvari, 2003, p. 240, apud Gomes \& Ferraz, 2012, p. 303).

Estima-se que um pouco mais de um quarto da população mundial foi contaminada pela gripe espanhola. No Brasil foram estipulados mais de 35 mil óbitos, dentre os infectados o eleito à presidência Rodrigues Alves, que faleceu antes de assumir seu segundo mandato como presidente (Loss, 2020).

Percebe-se, assim, que toda e qualquer pandemia deve ser tratada com seriedade, segundo mostra a experiência de uma testemunha da gripe espanhola no Brasil:

O pior de tudo é que estava morrendo gente aos borbotões, e o governo dizia, nas ruas e nas folhas, que a gripe era benigna. Certo dia, as folhas noticiaram mais de quinhentos óbitos, e mesmo assim a gripe era benigna, benigna, benigna. (...) As mortes eram tantas que não se dava conta do sepultamento dos corpos. Na minha rua, da janela, se via um oceano de cadáveres (Goulart, 2005, p.109). 
Nota-se o quão importante é aprender com a história do nosso país e do mundo, sobretudo no que se refere à conscientização dos órgãos públicos sobre a seriedade de problemas de saúde pública. Estamos em uma nova era, na qual os avanços da medicina e da tecnologia têm sido significativos, embora isso não nos impeça de vivenciar o caos, como vem ocorrendo em diversos países do globo. No Brasil, a desigualdade social é um fator agravante, uma vez que a população mais pobre é a mais suscetível aos impactos da nova pandemia.

Diante do cenário de emergência da pandemia do COVID-19 no Brasil, o presente artigo lança um olhar crítico ao discurso do presidente da República do Brasil Jair Messias Bolsonaro em relação à crise sanitária de 2020. Sendo assim, adotamos como recorte para este estudo os cinco discursos de maior repercussão proferidos pelo presidente brasileiro no período compreendido entre 9 de março de 2020 e 12 de abril de 2020.

\section{Metodologia}

Para analisar os discursos realizados pelo presidente brasileiro este estudo seguiu a linha proposta pelos autores Fairclough \& Melo (2012), que acreditam que a análise crítica do discurso parte da problemática social, tendo em vista objetivos que ajudem a solucionar problemáticas que sejam danosas à sociedade. Nesta perspectiva, foram escolhidos cinco discursos do presidente Jair Messias Bolsonaro para realização de uma análise crítica, nomeadamente aqueles proferidos nos dias 9 de março de 2020, 20 de março de 2020, 24 de março de 2020, 26 de março de 2020 e 12 de abril de 2020.

Logo, este trabalho tem como princípio uma abordagem teórico-analítica do objeto em questão, a fim de compreender o poder de um discurso, que pode muitas vezes pôr em risco milhares de vidas. O presente estudo não possui a finalidade de obter resultados a partir de análises numéricas quantitativas, mas leva em consideração a análise qualitativa acerca dos fatos. Ainda assim, percebeu-se a necessidade de tornar explícito alguns dados e números referentes à pandemia, como os disponibilizados pela Organização Mundial da Saúde (OMS) e pelo Ministério da Saúde no Brasil. 


\section{Resultados e Discussão}

\subsection{A pandemia no Brasil e os discursos do presidente}

O primeiro caso confirmado do coronavírus no Brasil surgiu no dia 26 de fevereiro de 2020, em São Paulo, enquanto o primeiro caso confirmado na Itália, país apontado como pioneiro em COVID-19 no Ocidente, ocorreu cerca de um mês antes, no dia 30 de janeiro (G1, 2020a). Segundo dados da revista Saúde, o primeiro caso em território brasileiro foi o de um senhor de 61 anos que vinha da Itália, considerada também o segundo país mais afetado até o início de abril de 2020 pelo COVID-19 (Pinheiro \& Ruprecht, 2020). Com o intuito de comparar a propagação do vírus no Brasil e na Itália, foi desenvolvida a Figura 1, que mostra a evolução da transmissão nos 30 dias subsequentes ao primeiro caso.

Figura 1 - A evolução do COVID-19 no Brasil e na Itália.

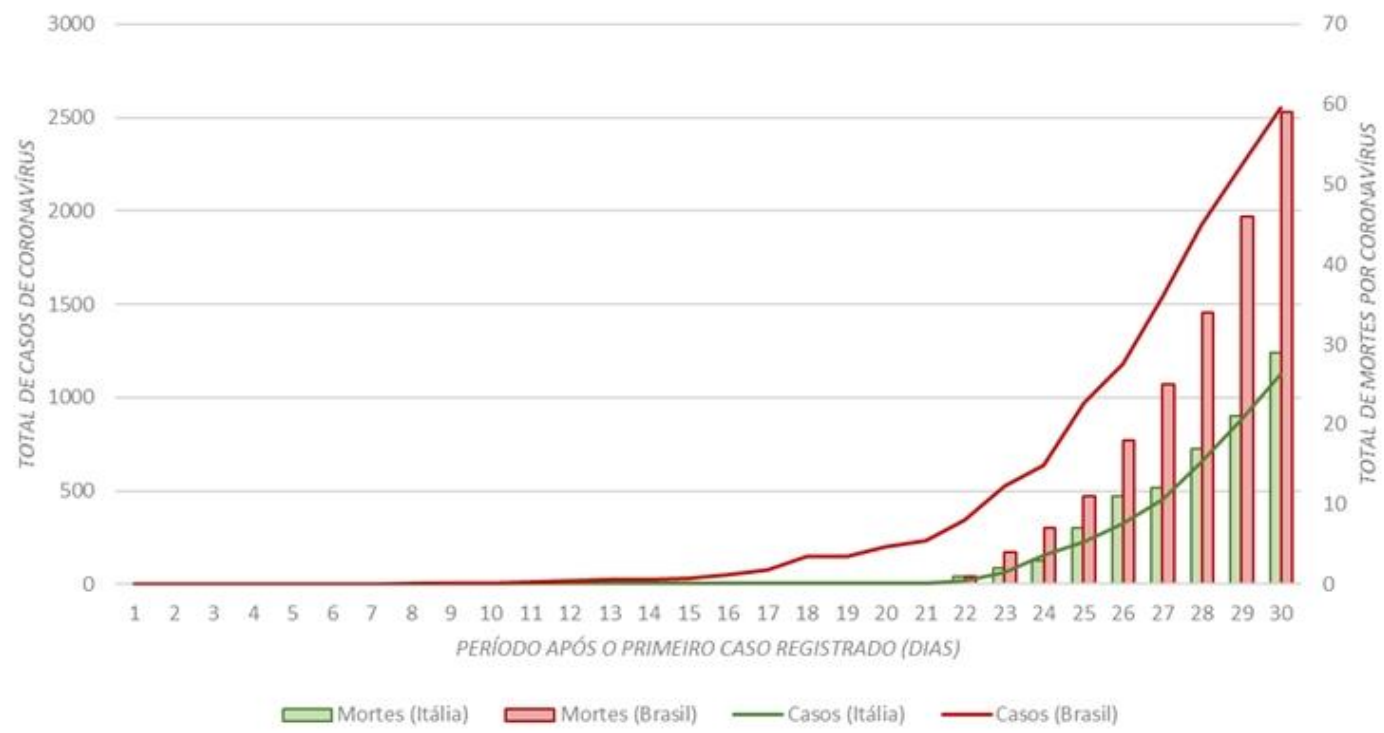

Fonte: Dados da OMS e Ministério da Saúde, com produção dos autores.

Os dados mostram que o Brasil apresenta cerca de 50\% mais mortes registradas oficialmente que a Itália em seus primeiros trinta dias após o registro da primeira vítima. Percebe-se que esses números servem de alerta para manter a sociedade em isolamento. Especialistas acreditavam que o pico da infecção se daria após um mês do primeiro contágio, já que em nenhum desses países o pico de contágio ocorreu antes que se completasse um mês (Polato \& Muraro, 2020). 
Nessa perspectiva, alguns dados do Ministério da Saúde foram analisados por um estudo desenvolvido pelo Departamento de Física da Universidade de São Paulo (USP), que mostrou que o isolamento social colabora de forma positiva para a diminuição das contaminações da COVID-19. “Os dados não refletem uma tendência e são um retrato do que aconteceu desde o primeiro caso confirmado da doença no Brasil, isso indica para a gente quais são as políticas a serem seguidas" (Moraes, 2020).

Logo, sabemos que o coronavírus está deixando diversas feridas no mundo, sejam elas econômicas ou sociais, que exigem da população e de seus líderes políticos cuidado, união e comprometimento para combater essa crise, a fim de minimizar as problemáticas. No Brasil, uma das principais polêmicas sobre o tema têm sido as falsas informações divulgadas sobre a doença e os posicionamentos questionáveis do presidente Jair Messias Bolsonaro.

Apesar dos números se revelarem crescentes nas semanas seguintes ao primeiro caso registrado, o presidente desde o início minimizou a crise mundial, destacando que a preocupação e os esforços para combater o coronavírus eram uma histeria coletiva e que o assunto vinha sendo superdimensionado pela mídia. É o que ele relata em seu primeiro discurso $^{1}$ sobre o tema, proferido em 9 de março de 2020, durante uma comitiva do governo brasileiro em Miami, nos Estados Unidos. Na ocasião, o líder político também afirmou que uma das intenções da mídia é causar pânico na população (Veja, 2020).

Tal discurso causa estranheza, pelo descaso com o exemplo vivenciado nos outros países e porque Jair Bolsonaro preferiu ir na contramão das medidas adotadas globalmente, apenas para combater uma crise econômica que já seria realidade, no momento em que a maior prioridade deveria ser o combate ao vírus que ameaça a vida de milhões de pessoas.

O presidente também ressaltou, em seu segundo discurso ${ }^{2}$ após o início da pandemia, proferido no dia 20 de março de 2020, que apenas uma "gripezinha" não iria derrubá-lo nem fazer o Brasil parar (Brito, 2020). Até o dia 23 de março de 2020, segundo Uribe (2020), 23 pessoas que acompanharam Jair Bolsonaro na comitiva presidencial aos Estados Unidos testaram positivo para a infecção pelo coronavírus. O presidente, que foi submetido a exames, negou publicamente por diversas vezes a infecção, mas pelo menos até 9 de maio de 2020 não havia mostrado os resultados, mesmo diante de pressões judiciais (Ferreira \& Galf, 2020).

\footnotetext{
${ }^{1}$ Disponível em: https://www.youtube.com/watch?v=VTCHQkJqv3I. Acesso em 27 de março de 2020.

${ }^{2}$ Disponível em: https://www.youtube.com/watch?v=ts2ClqnHKWA\&t=50s. Acesso em: 27 de março de 2020.
} 
Então, no dia 24 de março de 2020, em seu terceiro discurso ${ }^{3}$ para milhões de brasileiros, o presidente voltou a relativizar a pandemia instaurada no mundo. Jair Bolsonaro foi novamente de encontro às recomendações dos especialistas para permanecer em quarentena, contrariando até mesmo o seu então ministro da Saúde Luiz Henrique Mandetta, que alertava que se não fosse seguido "o máximo grau de isolamento social" no final do mês de abril deste ano o sistema de saúde entraria em colapso (Bertoni, 2020). Entretanto, o presidente permaneceu afirmando que "devemos sim voltar à normalidade" e que por causa do seu "histórico de atleta" teria no máximo "uma gripezinha ou um pequeno resfriado". Esta última frase foi prontamente rebatida por especialistas, que afirmam que a prática de exercícios no passado não torna qualquer pessoa idosa mais resistente a uma infecção (Roxo, 2020).

Os pronunciamentos polêmicos do presidente também viraram notícia em diversos meios de comunicação internacionais. Jornais de Portugal, Espanha, Inglaterra e França, como ilustrado na Figura 2, analisaram o pronunciamento e caracterizaram Jair Bolsonaro como "incendiário" e "inacreditável", reiterando que o presidente estaria indo contra as recomendações dos especialistas do mundo todo (Braun, 2020).

Figura 2 - Manchetes internacionais sobre o discurso do presidente.

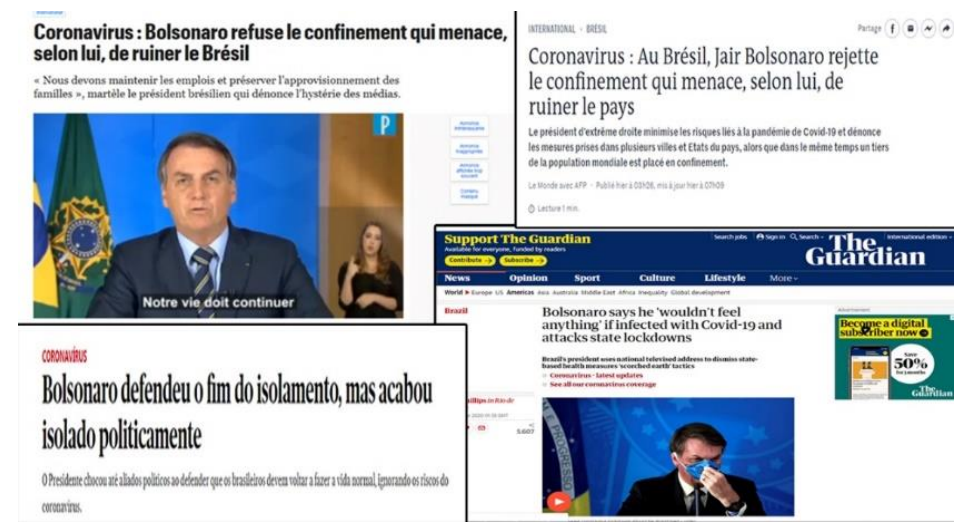

Fonte: Adaptado dos portais https://www.theguardian.com, https://www.publico.pt, https://www.lemonde.fr e https://www.leparisien.fr.

O fato é que após seu discurso polêmico contra o isolamento social, Jair Bolsonaro acabou ficando isolado politicamente, como retrata a manchete do jornal Público, de Portugal (J. R. Ribeiro, 2020). Logo na primeira fase da pandemia, após a confirmação dos casos pioneiros, os governadores de diversos Estados do Brasil se reuniram e começaram a tomar as

\footnotetext{
${ }^{3}$ Disponível em: https://www.youtube.com/watch?v=Tb22dopGGzI\&t=157s-. Acesso em 27 de março de 2020.
} 
devidas providências para combater o coronavírus, mesmo sem terem o apoio do presidente da República.

No dia 26 de março de 2020, em seu quarto discurso ${ }^{4}$ após o surgimento da pandemia, Jair Bolsonaro afirmou que o uso de substâncias como cloroquina e hidroxicloroquina deveriam fazer parte do tratamento, ressaltando: "aplica logo, pô", negando a existência de qualquer efeito colateral (W. Ribeiro, 2020). Entretanto, especialistas declararam como inconclusos até aquele momento os estudos sobre a eficácia do uso de tais substâncias. Segundo uma pesquisa desenvolvida por 26 pesquisadores brasileiros da equipe CloroCovid19 em Manaus, os pacientes que receberam as substâncias tinham desenvolvido arritmias cardíacas e, entre aqueles que receberam uma dosagem de 600 miligramas, cerca de 27,5\%, chegaram a óbito após o sexto dia de tratamento (Vivabem, 2020). Porém, diante de todo caos, Bolsonaro continuou fazendo alusões e brincadeiras na intenção de relativizar a gravidade da situação no país, uma vez que nesse mesmo discurso afirmou que o "brasileiro pula em esgoto e não acontece nada" (Gomes, 2020).

No mesmo dia do discurso aqui destacado, 26 de março de 2020, após serem contabilizadas 5.402 mortes e mais de 37 mil casos por conta do COVID-19 na Itália, o prefeito de Milão, Giuseppe Sala, admitiu que errou em ter se manifestado contra o isolamento social (O Globo, 2020). No dia 27 de março de 2020, o país tornou-se até então o mais afetado pela doença, quebrando novamente o seu recorde diário e registrando 919 mortes em apenas 24 horas. O presidente do Instituto Superior de Saúde (ISS) da Itália, Silvio Brusaferro, afirmou que ainda não havia atingido o pico de contágio. Até 21 de abril de 2020 foram registradas 24.111 mortes decorrentes do COVID-19, o sistema de saúde do país entrou em colapso e médicos foram obrigados a escolher quem teria prioridade por equipamentos de saúde, uma vez que não existia infraestrutura suficiente para comportar todos os enfermos (Pinto, 2020). O drama vivenciado pela nação italiana demonstra que a postura do presidente Jair Bolsonaro contrária à medida emergencial de isolamento social no Brasil tem sido no mínimo irresponsável e potencialmente genocida (Campos, 2020).

No domingo de Páscoa, 12 de abril de 2020, em uma transmissão feita com líderes religiosos do país que durou um pouco mais de duas horas, o presidente Jair Bolsonaro relatou em seu quinto discurso ${ }^{5}$ que o vírus "parece estar desaparecendo". A declaração contrapõe os

\footnotetext{
${ }^{4}$ Disponível em: https://www.dw.com/pt-br/em-pronunciamento-bolsonaro-defende-uso-da-cloroquina-contracovid-19/a-53069991. Acesso em 29 de março de 2020.
}

${ }^{5}$ Disponível em: https://www.youtube.com/watch?v=-VhRm0yRJKM. Acesso em 22 de abril de 2020. 
dados do próprio Ministério da Saúde em um período em que os casos continuam aumentando dia após dia. Tal postura estimula os cidadãos a saírem da quarentena e confronta as recomendações da Organização Mundial de Saúde e do próprio Ministério da Saúde, que pedem para as pessoas permanecerem em quarentena (Arias, 2020).

O mundo segue em colapso, com países como os Estados Unidos registrando 740 mil casos até o dia 19 de abril de 2020, em curva de crescimento acelerado, segundo a Universidade Johns Hopkins (G1, 2020b). O Presidente Donald Trump não relativizou a gravidade da situação e adotou medidas emergenciais, fazendo com que o Senado aprovasse um pacote histórico de cerca de dois trilhões de dólares para auxiliar seus trabalhadores, autônomos, empresários, seu sistema de saúde e todos os outros setores que necessitam de ajuda (Teodoro, 2020).

Em 7 de maio de 2020, data de conclusão das análises deste estudo, o Brasil registava oficialmente 135.106 casos confirmados em todo o seu território e 9.146 mortes (Ministério da saúde, 2020). Esperava-se que o pico de contágio de COVID-19 acontecesse até o final de abril; entretanto, com a adesão ao menos parcial do isolamento social, esse pico foi revisado para os meses de maio e junho de 2020. Ainda assim, alguns especialistas afirmam que esse pico pode não acontecer, mantendo-se uma linha horizontal de contaminação no Brasil (Vidale, 2020).

\subsection{A midiatização do COVID-19: a mídia como agente de mudança social}

Quando se procura entender o conceito da palavra mídia, está sempre abrange várias perspectivas midiáticas. Em tese, faz-se uma relação direta a um ecossistema comunicativo que envolve desde as plataformas de disseminação de conteúdo online aos mais diversos meios de comunicação com a sociedade, como revistas, jornais, rádio, televisão etc.

Sendo assim, é possível notar, segundo Kaplún (1999, p.75), que quando a comunicação é “...edificada pelo diálogo, a cooperação solidária e a reafirmação das identidades culturais, o desenvolvimento da competência comunicativa dos sujeitos atuantes aparece como um fator altamente necessário", tendo um peso educacional importante para o desenvolvimento do indivíduo.

Nessa perspectiva percebe-se que com o passar do tempo as tecnologias também têm avançado, aumentando gradativamente a presença da mídia na sociedade, seja ela televisiva, escrita, falada ou qualquer outro meio de comunicação que surge ao longo dos tempos. $\mathrm{O}$ fato é que a mídia está presente o tempo inteiro e ao nosso redor (Guareschi, 2006), quando 
ligamos a TV, quando acessamos algum site, ou quando entramos em alguma rede social, estamos sempre absorvendo informações instantâneas do mundo inteiro, em um piscar de olhos.

Diante disso, a mídia tem um papel essencial nas nossas vidas, para informar, expor ideias, alertar e até mesmo, dependendo do tipo de informação, alienar os telespectadores. A partir do incremento do digital, vem se tornando cada vez mais acessível criar a própria rede de comunicação, possibilitando que qualquer pessoa produza e propague seus conteúdos, independente de terem ou não tanta credibilidade assim (Rainie \& Wellman, 2012).

Porém, o jornalismo feito com seriedade e comprometimento pode ser uma ferramenta eficaz para verificar a veracidade das informações postadas na web, conscientizar e alertar a população sobre o tipo de problema que estamos enfrentando. No Brasil, para além do negacionismo dos perigos da pandemia do novo coronavírus, o presidente Jair Bolsonaro também vem tentando diminuir e ironizar o trabalho da mídia na sociedade, aliando o pensamento da sua base de apoiadores também contra emissoras, periódicos, redes de comunicação e profissionais, em geral, que o criticam. Um exemplo disso foi o seu pronunciamento durante a comitiva do Governo Federal a Miami, no dia 9 de março de 2020, quando o presidente afirmou que a mídia só queria causar histeria em torno da divulgação das notícias relacionadas à pandemia.

A mídia brasileira e internacional, entretanto, vem trabalhando no combate ao coronavírus, a fim de alertar, informar, conscientizar e proteger cada vez mais a população, exercendo a sua função pedagógica (Cerqueira, 2018). Apesar disso, no dia 28 de março de 2020, o então ministro da Saúde Luiz Henrique Mandetta chamou a mídia de "sórdida" em uma entrevista, justificando que a imprensa só vende notícia se a matéria for ruim (Uol, 2020).

A jornalista Ana Paula Araújo, apresentadora diversos telejornais na Rede Globo, uma das maiores redes de comunicação do Brasil que vem sofre constantes ataques por parte do governo Bolsonaro, rebateu a crítica do ministro no mesmo dia, na edição do Jornal Nacional:

O ministro da Saúde encontrou outra maneira de agradar o presidente: criticou o trabalho da imprensa, afirmando que os meios de comunicação são sórdidos, porque na visão dele só vendem se a matéria for ruim. Na pandemia de um vírus letal contra o qual não há medicamento ou vacina é estarrecedor que ele não reconheça que o nosso trabalho, o trabalho de todos os colegas jornalistas, daqui da Globo, mas também de todos os veículos, é um remédio poderoso: dar informação para que o povo possa se proteger. Há muitos trabalhos essenciais, dos médicos e enfermeiros em primeiro 
lugar, mas nós jornalistas estamos nas redações e nas ruas arriscando nossa saúde, para cumprir nossa missão. E fazemos isso com orgulho (Globo, 2020).

Portanto, por um lado, é importante que a audiência seja crítica para distinguir as informações e não se deixar levar pela manipulação de alguns meios tendenciosos. Por outro, é importante reconhecer o papel da mídia e do jornalismo feito com compromisso social. A mídia carrega um papel educativo de muita importância para a sociedade nesses tempos de crise, pois é através dela que é possível combater discursos perigosos e contraditórios, realizando o trabalho de informar, alertar e ajudar a proteger as pessoas de ameaças como a pandemia.

Sendo assim, o jornalismo nos tempos de hoje, em que o governo tenta a todo o momento colocar a sociedade contra as fontes de informação dos media tradicionais, tem se tornado cada vez mais necessário e urgente. Principalmente, para informar as camadas mais pobres ou pouco escolarizadas, que muitas vezes aprendem através da televisão, por meio dos seus programas de entretenimento e dos telejornais.

\section{Considerações Finais}

Percebe-se, diante deste estudo, que a pandemia do novo coronavírus, relativamente recente e ainda em curso, tem tomado grandes proporções, infectando pessoas do mundo todo. Embora atualmente não exista a cura, atitudes como o isolamento social podem salvar vidas e desacelerar a propagação do coronavírus.

Ao longo das análises do corpus selecionado, percebeu-se que em seu primeiro discurso sobre o tema, proferido em Miami, o presidente da república Jair Bolsonaro tratou a pandemia como alarme da mídia, mesmo seu discurso tendo acontecido no mesmo dia que a Itália presenciava um pico no número de mortos. Tal discurso influenciou parte da população, fazendo com que muitos que vivem no Brasil desacreditassem do poder letal do vírus, fato que provocou indiretamente a realização de protestos presenciais em diversas cidades do Brasil, a flexibilização do isolamento e o maior contágio entre a população.

Diante de uma miríade de críticas à fala do presidente, seja por meio de estudos científicos ou pelas abordagens do tema na mídia, esperava-se que Jair Bolsonaro mudasse de postura nos dias subsequentes, diante do aumento de casos e mortes no Brasil, o que não ocorreu. Em seu segundo discurso, Bolsonaro considerou o coronavírus como uma 
"gripezinha" que não iria parar o Brasil, subestimando mais uma vez o poder de letalidade do vírus e buscando minimizar a problemática mundial.

Em um terceiro discurso transmitido por todas as emissoras e meios de informação, Bolsonaro declarou outra vez que a população deveria "voltar à normalidade". Uma atitude mais uma vez questionável, indo de encontro às recomendações de isolamento da OMS e do próprio Ministério da Saúde.

Mesmo diante da seriedade do assunto, o presidente insistiu em fazer alusões e brincadeiras, chegando a mencionar em seu quarto discurso que "o brasileiro pula em esgoto e não acontece nada". Mas parece que não é bem assim, os dados são crescentes e alarmantes, na quarta semana de abril o Brasil já contabilizava mais de cinco mil óbitos no total, número que dobrou na primeira semana do mês posterior.

Sabendo que o papel educacional da mídia tem sido fundamental, percebe-se que é importante valorizar o trabalho que os agentes de comunicação fazem nesse momento de pandemia. Sem dúvidas, a educação através da informação vem sendo um meio de combater esse vírus que tomou conta do mundo inteiro, fazendo com que a população se conscientize sobre a gravidade do problema que estamos enfrentando. Com a população consciente das precauções necessárias, estaremos mais próximos de minimizar a propagação do vírus e de controlar a pandemia, que em seus primeiros meses já mostrou a sua letalidade, desafiando discursos políticos que tentam relativizar seus impactos na vida humana.

Por fim, ainda é cedo para analisar de forma definitiva os impactos dos discursos do presidente Jair Bolsonaro no Brasil contemporâneo. Ainda assim, este estudo tenta contribuir um ponto de partida para reflexões sobre a problemática do discurso presidencial no tocante ao enfrentamento da pandemia de COVID-19. Sugere-se que novos trabalhos sejam desenvolvidos para dar continuidade às análises discursivas a fim de mensurar os impactos das falas presidenciais e o desdobramento da pandemia a médio e longo prazo.

\section{Referências}

Abroug, F., Slim, A., Ouanes-Besbes, L., Kacem, M. A. H., Dachraoui, F., Ouanes, I., ... \& Miao, C. (2014). Family cluster of Middle East respiratory syndrome coronavirus infections, Tunisia, 2013. Emerging infectious diseases, 20(9), 1527. 
Arias, J. (2020). El País. Na mensagem de Páscoa, Bolsonaro mentiu e insultou a inteligência da nação. Acesso em 21 de abril de 2020, em https://brasil.elpais.com/opiniao/2020-04-14/namensagem-de-pascoa-bolsonaro-mentiu-a-nacao-e-insultou-sua-inteligencia.html.

Bertoni, E. (2020). Como Mandetta se posiciona diante da atitude do chefe na pandemia. Acesso em 25 de março de 2020, em https://www.nexojornal.com.br/expresso/2020/03/25/Como-Mandetta-se-posiciona-diante-daatitude-do-chefe-na-pandemia.

Braun, J. (2020) Imprensa internacional repercute discurso de Bolsonaro. Acesso em 25 de março de 2020, em https://veja.abril.com.br/mundo/imprensa-internacional-repercutediscurso-incendiario-de-bolsonaro/.

Brito, R. (2020) Bolsonaro volta a se referir ao coronavírus como gripezinha, critica governadores e gera reação. Acesso em 24 de março de 2020, em https://economia.uol.com.br/noticias/reuters/2020/03/24/bolsonaro-volta-a-se-referir-aocoronavirus-como-gripezinha-e-criticar-governadores-por-restricoes.htm.

Campos, L. H. (2020) Um mês depois de campanha para Milão não parar, região da cidade italiana tem mais de 4 mil mortos. Acesso em 27 de março de 2020, em https://oglobo.globo.com/mundo/apos-5402-mortes-prefeito-de-milao-admitiu-erro-de-terapoiado-campanha-para-cidade-nao-parar-24332774.

Cerqueira, L. (2018). A Função Pedagógica do Telejornalismo: e os Saberes de Paulo Freire na Prática Jornalística de Cerqueira. Florianópolis, SC: Editora Insular.

Fairclough, N., \& de Melo, I. F. (2012). Análise crítica do discurso como método em pesquisa social científica. Linha d'agua, 25(2), 307-329.

Ferreira, F \& Galf, R. (2020) Entenda possíveis crimes de Bolsonaro em torno da disputa judicial sobre seu exame de coronavírus. Acesso em 9 de maio de 2020, em https://www1.folha.uol.com.br/poder/2020/05/entenda-possiveis-crimes-de-bolsonaro-emtorno-da-disputa-judicial-sobre-seu-exame-de-coronavirus.shtml. 
G1. (2020a) Itália confirma primeiros casos de coronavírus no país. Acesso em 30 de janeiro de 2020, em https://g1.globo.com/ciencia-e-saude/noticia/2020/01/30/italia-confirmaprimeiros-casos-de-coronavirus-no-pais.ghtml.

G1. (2020b). Mortes por Covid-19 nos EUA passam de 40 mil. Acesso em 19 de abril de 2020, em https://g1.globo.com/bemestar/coronavirus/noticia/2020/04/19/mortes-por-Covid19-nos-eua-passam-de-40-mil.ghtml.

Globo. (2020). globo responde crítica de mandetta contra a imprensa. acesso em 12 de abril de 2020, em https://veja.abril.com.br/entretenimento/globo-responde-critica-de-mandettacontra-a-imprensa/.

Gomes, I. M. D. A. M., \& Ferraz, L. M. R. (2012). Ameaça e controle da gripe A (H1N1): uma análise discursiva de Veja, IstoÉ e Época. Saúde e Sociedade, 21(2), 302-313.

Gomes, P. H. (2020). Brasileiro pula em esgoto e não acontece nada, diz Bolsonaro em alusão a infecção pelo coronavírus. Acesso em 26 de março de 2020, em https://g1.globo.com/politica/noticia/2020/03/26/brasileiro-pula-em-esgoto-e-nao-acontecenada-diz-bolsonaro-em-alusao-a-infeccao-pelo-coronavirus.ghtml.

Goulart, A. C. (2005). Revisitando a espanhola: a gripe pandêmica de 1918 no Rio de Janeiro. v. 12 , n. 1, pp. 101-142.

Guareschi, P. (2006). Mídia e Cidadania. In: Conexão - Comunicação e Cultura, UCS, Caxias do Sul, v. 5, n. 9, p. 27-40.

Kaplún, M. (1999). Processos educativos e canais de comunicação. In: Comunicação \& Educação, n. 14, pp. 68-75.

Loss, G. (2020). Conheça as maiores pandemias da história: do coronavirus a gripe espanhola. Acesso em 23 de março de 2020, em https://diariodamanha.com/noticias/conheca-as-maiorespandemias-da-historia-do-coronavirus-a-gripe-espanhola/. 
Ministério da Saúde. (2020). Brasil registra 135.106 casos de coronavírus e 9.146 mortes pela doença. Acesso em 9 de maio de 2020, em https://www.saude.gov.br/noticias/agenciasaude/46852-brasil-registra-135-106-casos-de-coronavirus-e-9-146-mortes-pela-doenca.

Moraes, C. (2020). Levantamento mostra que isolamento começou a achatar a curva de coronavírus em SP. Acesso em 27 de março de 2020, em https://www1.folha.uol.com.br/amp/cotidiano/2020/03/levantamento-mostra-que-isolamentocomecou-a-achatar-a-curva-de-coronavirus-emsp.shtml?utm_source=twitter\&utm_medium =social\&utm_campaign=twfolha\&_twitter_impr ession=true\&fbclid=IwAR1owodn2Y_3w8MLDvOudlEQn6HeXpuMXrXW_bXg2u5xQUW wh1snWg0JRUY.

Nippon Hōsō Kyōkai. (2020). Número de mortes por coronavírus chega a 2.788 casos na China. Acesso em 19 de abril de 2020, em https://agenciabrasil.ebc.com.br/internacional/noticia/2020-02/numero-de-mortes-porcoronavirus-chega-2788-casos-na-china.

O Globo. (2020). Após 5.402 mortes, prefeito de Milão admitiu erro de ter apoiado campanha para cidade não parar. Acesso em 27 de março de 2020, em https://oglobo.globo.com/mundo/apos-5402-mortes-prefeito-de-milao-admitiu-erro-de-terapoiado-campanha-para-cidade-nao-parar-24332774.

Organização Pan-Americana da Saúde/Organização Mundial da Saúde Brasil. (2020). Folha informativa - COVID-19 (doença causada pelo novo coronavírus). Acesso em 8 de maio de 2020, em

https://www.paho.org/bra/index.php?option=com_content\&view=article\&id=6101:covid19\&I temid $=875$.

Pinheiro, C. \& Ruprecht, T. (2020). Coronavírus: primeiro caso é confirmado no brasil. o que fazer agora?. Acesso em 26 de fevereiro de 2020, em https://saude.abril.com.br/medicina/coronavirus-primeiro-caso-brasil/.

Pinto, A. E.S. (2020). Itália registra 919 novas mortes, maior número diário desde início da pandemia do coronavírus. Acesso em 27 de março de 2020, em 
https://www1.folha.uol.com.br/equilibrioesaude/2020/03/italia-registra-919-novas-mortesmaior-numero-diario-desde-inicio-da-pandemia-do-coronavirus.shtml.

Polato, A \& Muraro, C. (2020). 1 mês de coronavírus no Brasil: compare a situação do país com China, Itália, EUA e Coreia do Sul no mesmo período da epidemia. 2020. Acesso em 26 de março de 2020, em https://g1.globo.com/bemestar/coronavirus/noticia/2020/03/26/1-mesde-coronavirus-no-brasil-compare-a-situacao-do-pais-com-china-italia-eua-e-coreia-do-sulno-mesmo-periodo-da-epidemia.ghtml.

Rainie, L. \& Wellman, B (2012). Networked: The New Social Operating System. Cambridge, Massachusetts, EUA: MIT Press.

Ribeiro, J. R. (2020). Bolsonaro defendeu o fim do isolamento, mas acabou isolado politicamente. Acesso em 27 de março de 2020, em https://www.publico.pt/2020/03/25/mundo/noticia/bolsonaro-defendeu-fim-isolamentoacabou-isolado-politicamente-1909462.

Ribeiro, W. (2020). "Cloroquina não tem efeito colateral" afirma bolsonaro. Acesso em 21 de abril de 2020, em https://www.ictq.com.br/politica-farmaceutica/1328-cloroquina-nao-temefeito-colateral-afirma-bolsonaro.

Roxo, S. (2020). Médicos contestam resistência de Bolsonaro ao coronavírus por ter sido atleta. Acesso em 03 de abril de 2020, em https://oglobo.globo.com/brasil/medicoscontestam-resistencia-de-bolsonaro-ao-coronavirus-por-ter-sido-atleta-24329589.

Souza, A. (2020). Antes de pronunciamento de Bolsonaro, Ministério da Saúde recomendou em redes sociais evitar sair de casa. Acesso em 28 de março de 2020, em https://oglobo.globo.com/sociedade/antes-de-pronunciamento-de-bolsonaro-ministerio-dasaude-recomendou-em-redes-sociais-evitar-sair-de-casa-24330308.

Surveillances, V. (2020). The epidemiological characteristics of an outbreak of 2019 novel coronavirus diseases (COVID-19) - China, 2020. China CDC Weekly, 2(8), 113-122. 
Tang, X., Wu, C., Li, X., Song, Y., Yao, X., Wu, X., ... \& Cui, J. (2020). On the origin and continuing evolution of SARS-CoV-2. National Science Review. Acesso em 25 de abril de 2020, em https://academic.oup.com/nsr/advance-article/doi/10.1093/nsr/nwaa036/5775463.

Teodoro, P. (2020). Coronavírus: mundo passa dos 500 mil infectados; eua lideram com 82,6 mil casos. Acesso em 28 de março de 2020, em https://revistaforum.com.br/coronavirus/coronavirus-mundo-passa-dos-500-mil-infectadoseua-lideram-com-826-mil-casos/.

Ujvari, S. C. (2008). A história da disseminação dos microrganismos. estudos avançados, 22(64), 171-182.

Uol. (2020). Mandetta diz que a imprensa é tóxica. Acesso em 03 de maio de 2020, em https://www.youtube.com/watch?time_continue=31\&v=6odJWxGG4-o\&feature=emb_logo.

Uribe, G. (2020). Veja quem são os 23 com coronavírus da comitiva de Bolsonaro que visitou os EUA: diagnosticados com a Covid-19 após viagem presidencial incluem dois ministros do governo. Acesso em 21 de abril de 2020, em https://www1.folha.uol.com.br/poder/2020/03/veja-quem-sao-os-23-infectados-da-comitivade-bolsonaro-em-visita-aos-eua.shtml.

Veja. (2020). Bolsonaro sanciona com vetos auxílio de $\mathrm{R} \$ 600$ a informais. Acesso em 1 de abril de 2020, em https://veja.abril.com.br/economia/bolsonaro-sanciona-auxilio-de-r-600-ainformais-diz-lider-do-governo/.

Vidale, G. (2020). Por que o pico do coronavírus no Brasil mudou para maio e junho?. Acesso em 02 de maio de 2020, em https://veja.abril.com.br/saude/por-que-o-pico-do-coronavirusno-brasil-mudou-para-maio-e-junho/.

Vivabem. (2020). Estudo com cloroquina é interrompido após efeitos colaterais em pacientes. Acesso em 13 de abril de 2020, em https://www.uol.com.br/vivabem/noticias/redacao/2020/04/13/estudo-com-cloroquina-einterrompido-apos-efeitos-colaterais-em-pacientes.htm. 
Research, Society and Development, v. 9, n. 7, e609974469, 2020

(CC BY 4.0) | ISSN 2525-3409 | DOI: http://dx.doi.org/10.33448/rsd-v9i7.4469

Porcentagem de contribuição de cada autor no manuscrito

Leonardo Pereira Tavares $-35 \%$

Francisco Lima de Oliveira Júnior - 30\%

Marina Magalhães - 35\% 